\title{
Physiological mechanism of resistance antibiosis to anthracnose of different Manihot varieties
}

\author{
Kouassi Guy BROU ${ }^{*}$, Jean Luc Aboya MOROH ${ }^{2}$, Sékou DIABATÉ ${ }^{3}$, Boni N'ZUE ${ }^{4}$, \\ Goli Pierre ZOUHOURI ${ }^{5}$, Janat Ackanovna MAMYRBEKOVA-BEKRO ${ }^{6}$, II Nazaire Koffi \\ $\mathrm{KOUASSI}^{7}$, Denézon Odette DOGBO $^{8}$ and Yves-Alain BEKRO ${ }^{6}$
}

\begin{abstract}
${ }^{1}$ Unité de Formation et de Recherche (UFR) des Sciences Biologiques, Département Biologie Végétal, Université Peleforo GON COULIBALY (UPGC). BP 1328 Korhogo, Côte d'Ivoire.

${ }^{2}$ Unité de Formation et de Recherche (UFR) des Sciences Biologiques, Département Biochimie Génétique, Université Peleforo GON COULIBALY (UPGC). BP 1328 Korhogo, Côte d'Ivoire.

${ }^{3}$ Unité de Physio/Phytopathologie, Laboratoire Central de Biotechnologie, Centre Nationale de Recherche Agronomique (CNRA), 01 BP 1740 Abidjan 01, Côte d'Ivoire.

${ }^{4}$ Station des cultures vivrières, Programme Plante à Racine et Tubercule, Centre Nationale de Recherche Agronomique (CNRA), 01 BP 1740 Abidjan 01, Côte d'Ivoire.

${ }^{5}$ Unité de Pathologie Moléculaire, Laboratoire Central de Biotechnologie, Centre Nationale de Recherche Agronomique (CNRA), 01 BP 1740 Abidjan 01, Côte d'Ivoire.

${ }^{6}$ Unité de Formation et de Recherche (UFR) des Sciences Fondamentales et Appliquées, Laboratoire de Chimie Bio-Organique et des Substances Naturelles, Université Nangui Abrogoua, 02 BP 801Abidjan 02, Côte d'Ivoire.

${ }^{7}$ Unité de Formation et de Recherche (UFR) des Biosciences, Programme West African Virus Epidemiology (WAVE), Université Félix Houphouët Boigny, 01 BPV 34 Abidjan 01, ex-Directeur du Laboratoire Central de Biotechnologie, Centre Nationale de Recherche Agronomique (CNRA), 01 BP 1740 Abidjan 01, Côte d'Ivoire. ${ }^{8}$ Unité de Formation et de Recherche (UFR) des Sciences Naturelles, Laboratoire de Biologie et Amélioration des Productions Végétales, Université Nangui Abrogoua, 02 BP 801Abidjan 02, Côte d'Tvoire.

*Corresponding author; E-mail: brookouassiguy@gmail.com; Tel. (00225) 09815077
\end{abstract}

\begin{abstract}
Cassava is one of the main food crops in Africa, particularly in Côte d'Ivoire. However, the cultivated varieties are prone to attack by diseases. The present work focused on the role of phenolic and in particular flavonoid resistance markers in the Manihot esculenta-Colletotrichum gloeosporioides pathosystem. The aim was to elucidate the involvement of flavonoid antibiosis in the natural defense of three cultivars of M. esculenta when confronted with attacks by $C$. gloeosporioides. The quantitative dosage approach for total phenolics and flavonoids as well as the identification of flavonoid antibiosis have been carried out. The results revealed that the cultivars 9620A, TMS30572 and YACE of M. esculenta have, after the C. gloeosporioides inoculation tests, reacted early 2 days after inoculation (JAI) and accumulated relatively high levels of antibiosis phenolic and flavonoid 9JAI. The three cultivars accumulated constitutive flavonoid antibiosis and 3 neosynthesized antibiosis from 7JAI to 9JAI. The accumulation of flavonoid antibacterials neosynthesized in the stems and in the leaves testify to the expression of a systemic resistance of the cassava plants. The cultivars 9620A and TMS30572 are more tolerant than cultivar YACE. This study approach has made it possible to discriminate between cultivars and can therefore be used as a complementary selection tool to traditional selection tests.
\end{abstract}

(C) 2020 International Formulae Group. All rights reserved.

Keywords: Manihot esculenta, anthracnose, flavonoïd antibisis, glyphosate. 


\section{INTRODUCTION}

In Côte d'Ivoire, Manihot esculenta Crantz, known as cassava, is a main food crop. It is cultivated for its tuberous roots and leaves all over the country (Brou, 2014; Akpingny et al., 2017), with an estimated annual production of around 5.367 million tonnes (Faostat, 2019), this plant is the second most important food crop after yam and before plantain (N'Zué et al., 2015; Konan et al., 2017). Cassava crop is an important source of income for the people who grow it (Ekou, 2003; Manso, 2005). Thus, in order to support the dynamics of the crop, several research programmes have focused on the improvement of locally produced varieties, or introduced from the International Institute of Tropical Agriculture (ITTA) via the National Centre for Agronomic Research (CNRA). However, despite the efforts made, the improved cultivars remain prone to many diseases (Onzo et al., 2012: Djinadou et al., 2018). Work carried out by Xinzhang et al. (2012) on Camelia oleifera and Lupinus angustifolius showed that in plants that accumulated high levels of antibiosis and Gogbe et al. (2016) chez des plants de palmiers infectés par Fusarium oxysporum fse, the pathogen Colletotrichum gloesporioides remained confined and the plants were found to be resistant. Therefore, the present work on the natural defense of Manihot esculenta in interaction with Colletotrichum gloeosporioides was undertaken with the aim of developing approaches for the selection of resistant / tolerant plants. Specifically, depending on the cultivars and the time of infection, it involved, on the one hand, evaluating the contents of total phenolic and total flavonoid antibiosis and, on the other hand, identifying flavonoid antibiosis.

\section{MATERIALS AND METHODS Plant Material}

The plant material used consists of 3 cultivars of Manihot esculenta of which one is traditional (YACE) and the other two improved 9620A (A), and TMS30572 (S). All these cultivars were supplied by the National Centre for Agronomic Research (CNRA).

\section{Fungal material}

The fungal agent used (Colletotrichum gloeosporioides f.sp. manihotis) is a necrotrophic fungus (Perfect et al., 1999). It was isolated from Manihot esculenta plants affected by anthracnose, on an experimental plot of the Centre National de Recherche Agronomique (CNRA). Colletotrichum gloeosporioides belongs to the order Melanconiales and the class Coelomycetes (Hawksworth et al., 1983). The conidia (Figure 25) are unicellular, elliptical or sickle-shaped, hyaline, without appendages and are produced apically on conidiophores in a sporiferous salmon- to orange-coloured jelly (Von Arx, 1981). Conidia and ascospores are embedded in a hydrophilic mucilaginous matrix of polysaccharides and glycoproteins. These matrices are water-soluble, with spores released and dispersed by the action of water (Louis \& Cooke, 1985; McRae \& Stevens, 1990).

\section{Methodology \\ Expérimental device}

Three blocks of plots (A, B and C) have been set up at the CNRA experimental site at Adiopodoumé in southern Côte d'Ivoire. Each block of plots consists of three (3) plots. Each plot consisted of three (3) rows of twenty (20) cassava plants arranged in totally randomized Fisher blocks.

\section{Inoculation}

The inoculation of the plants was done according to the methods of Terry et al. (1983), Ambang et al. (2007) and Brou (2014). It was carried out in 3 stages. The initial phase was the wounding of the stems, then the introduction of the inoculum in the form of a pellet at the wound site and finally the covering of the 
inoculated stem portion. This inoculation was carried out on 4-month-old plants. For this purpose, the plants were notched with a heated needle (Figure 1) on the portions of the lignifying stems located between the 5 th and 20th row of leaves from the apex of the plant (Figure 1). Three wound points were made on each plant (Ambang et al., 2007) and these were protected by sterilized transparent plastic wrapping the wounded stem portion to prevent possible infection. Thus, 50 wounded plants per cultivar on each plot were obtained. On the 4th day after the injury (Terry et al., 1983), 25 plants out of the 50 injured were selected to be inoculated by $C$. gloeosporioides. For this purpose, a $1 \mathrm{~cm} 2$ pellet of the 8-day old inoculum of $C$. gloeosporioides (consisting of $1.24 \times 106$ conidia counted on Malassez cells) was taken from petri dishes with a punch. This pellet was deposited at the site of the stem wound. After deposition of the inoculum, the inoculated stem portion was again covered with a new transparent plastic (Figure 32) which had been previously sterilized. Sterilization was performed by immersing the plastic in $\mathrm{NaOCl}(10 \%)$ for 3 min followed by abundant rinsing with sterilized distilled water. The positive control was represented by unharmed, uninoculated plants. The negative control was the wounded, uninoculated plants.

\section{Sampling and packaging of samples}

One day after inoculation, the leaves and stems of the 3 cultivars studied from Blocks A, B and C were sampled. The harvested organs were cleaned under running water and then dried for one day in a wellventilated room and then in an oven for 7 days at $45{ }^{\circ} \mathrm{C}$. The dried organs were pulverized with an electric mill (RETSCH, type SM 100) to obtain fine powders (Brou et al., 2012). These powders were used for hydro-methanol extraction (crude extracts) and selective extraction (flavonoid extracts).

\section{Quantification of phenolic and flavonoid antibiosis}

Extractions were carried out with the harvests of each block corresponding to the 115, 30, 45th DAI (Day After Inoculation) and the date of harvest of the tuberous roots (180 DAI). Thus, 324 extracts of which 162 for the leaves (54 uninjured, uninoculated extracts, 54 wounded/uninoculated extracts and 54 wounded, inoculated extracts) and 162 for the stems (54 uninjured, uninoculated extracts, 54 wounded, inoculated extracts and 54 wounded, inoculated extracts) were obtained. Each cultivar is presented by 18 extracts from the leaves and 18 extracts from the stems of unwounded and uninoculated plants (negative controls) (AFt, SFt, YFt, ATt, STt and YTt), by 18 extracts from leaves and 18 extracts from stems of injured/uninoculated plants (negative controls) (AFT, SFT, YFT, ATT, STT and YTT) and by 18 extracts from leaves and 18 extracts from stems of injured/inoculated plants (AFI, SFI, YFI, ATI, STI and YTI). A spectrophotometric assay of all these extracts (controls and inoculated) was carried out according to the protocol of Singleton and Rossi (1965), Brou et al. (2012), Dogbo et al. (2012) and Brou (2014).

\section{Identification of flavonoid antibiosis by Thin Layer Chromatography (TLC)}

TLC screening of the inoculated and positive controls extracts was carried out in order to identify the flavonoid antibiosis profile of cassava cultivars (Ekoumou, 2003; Dohou et al., 2003; Benkiki, 2006; Brou et al., 2010; Brou, 2014). The results of the extracts from uninjured-uninoculated plants (controls) obtained were compared with those of the extracts from injured-inoculated plants in order to show the role of phenolic antibiosis, in particular flavonoids, in the defense against anthracnose in Manihot esculenta. 


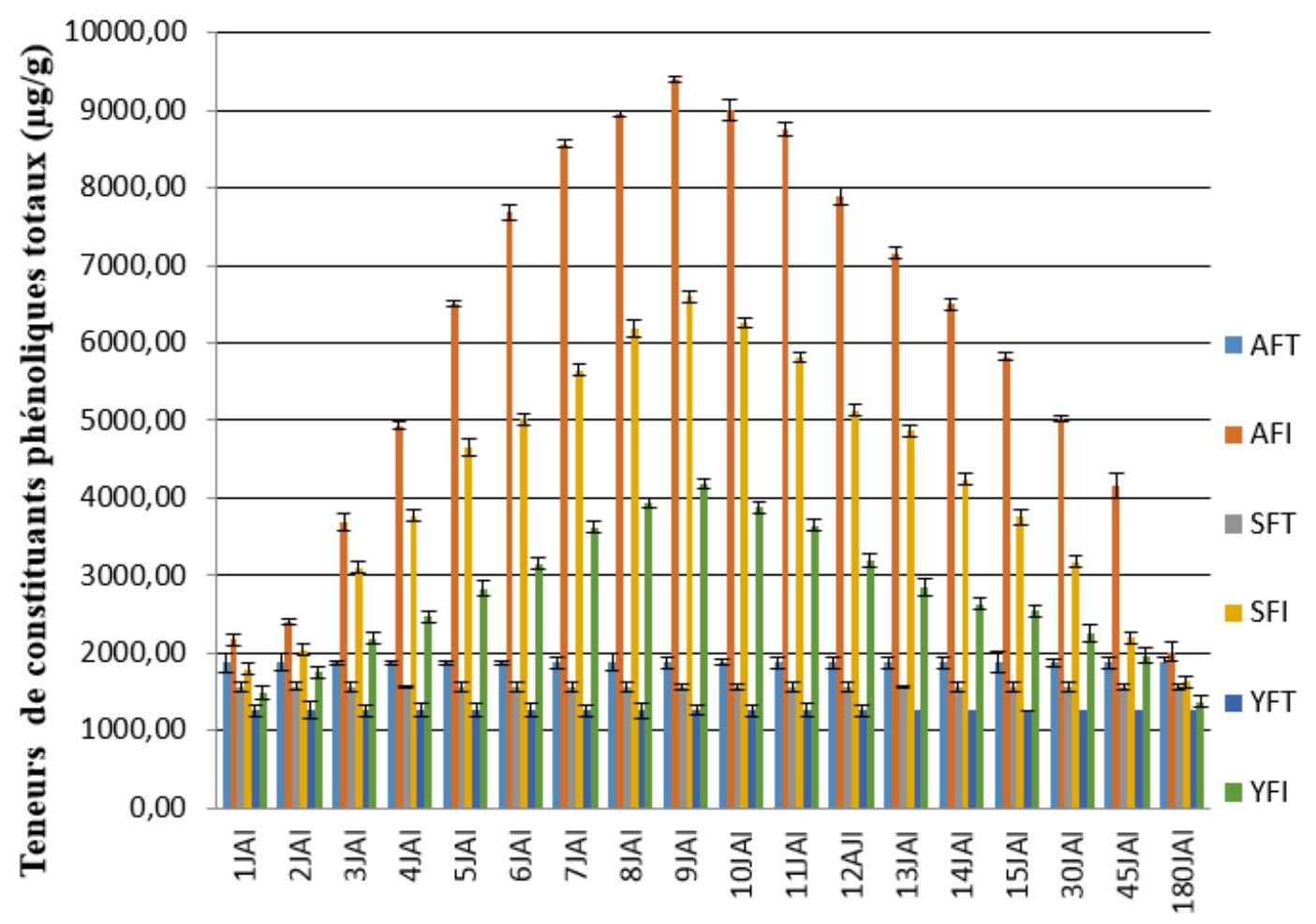

\section{Nombre de jours après inoculation des cultivars de Manihot esculenta}

Figure 1: Total phenolic antibiosis levels in leaves $(\mathbf{F})$ of inoculated $(\mathbf{I})$ and uninoculated $(\mathbf{T})$ Manihot esculenta cultivars (A, $\mathbf{S}$ and $\mathbf{Y})$ as a function of number of days.

DAI: day after inoculation; A: 9620A; S: TMS30572; Y: YACE; C: Controls.

\section{RESULTS}

Evaluation of total phenolic antibiosis content in the mechanism of resistance of three $M$. esculenta cultivars against $C$. gloeosporioides

The amounts of total phenolic antibiosis contained in the leaves and stems increased steadily and significantly after inoculation of the different cultivars with the inoculum of $C$. gloeosporioides (Figures 1 and 2; Tables 1 to 4). This was not the case in uninoculated plants (Figures 1 and 2; Tables 1 to 4). This increase began on the 2nd day of inoculation, and reached its optimum stimulation on the 9th day after inoculation (DAI). From the 10th DAI, the total phenolic antibiosis content decreased steadily to reach a value similar to that of the 1st DAI (Figures 1 and 2; Tables 1 to 4). The stimulation weir, determined from a significant weir value of total phenolic antibiosis according to Duncan's test $(\mathrm{F}=34.62 ; \mathrm{P}<$ 0.05), was the date from which the $M$. esculenta cultivar reacted significantly to aggression by $C$. gloeosporioides. Thus, these thresholds obtained after 2 DAI were 2405.23 $\pm 46.45 \mu \mathrm{g} / \mathrm{g}$ MS EAG, $2039.58 \pm 45.45 \mu \mathrm{g} / \mathrm{g}$ MS EAG and $1749.52 \pm 27.32 \mu \mathrm{g} / \mathrm{g}$ MS EAG at leaf level for cultivars $\mathrm{A}, \mathrm{S}$ and $\mathrm{Y}$ respectively (Figure 1; Tables 1 and 2). For stems, these weirs were $1057.62 \pm 16.78 \mu \mathrm{g} / \mathrm{g}$ MS EAG, $735.74 \pm 16.43 \mu \mathrm{g} / \mathrm{g}$ MS EAG and $513.64 \pm 15.95 \mu \mathrm{g} / \mathrm{g}$ MS EAG for cultivars A, 
$\mathrm{S}$ and $\mathrm{Y}$, respectively (Figure 2; Tables 3 and 4). As for the optimum stimulation or maximum accumulation stage, it was the date from which the cassava cultivar accumulated the highest amount of total phenolic antibiosis in its response to aggression by $C$. gloeosporioides. Thus, the optimum value for the leaves of cultivars $\mathrm{A}, \mathrm{S}$ and $\mathrm{Y}$ was $9012.31 \pm 32.45, \quad 6265.33 \pm 17.25$ and $3875.26 \pm 35.33 \mu \mathrm{g} / \mathrm{g}$ MS, respectively. Stems contained $5905.31 \pm 16.78,4626.01 \pm 14.63$ and $3779.45 \pm 13.74 \mu \mathrm{g} / \mathrm{g}$ MS for cultivars A, S and $\mathrm{Y}$, respectively. These maximum values were recorded on the $9^{\text {th }}$ DAI. At this stage of maximum accumulation, the leaves of cultivar A accumulated 5 times its phenolic antibiosis content and 8.51 times at the stem level. On the other hand, cultivar $\mathrm{S}$ accumulated 4.22 times its leaf and 9.25 times its stem accumulation, while the reference cultivar $\mathrm{Y}$ accumulated 3.32 and 7.22 times its constitutive phenolic content for leaves and stems, respectively. The proportions of accumulation of the improved cultivars (A and S) were higher than that of the reference cultivar $\mathrm{Y}$. The values recorded in each period were highest for cultivar A, medium for $\mathrm{S}$ and low for $\mathrm{Y}$. These values also varied with the organs. They were higher in the leaves than in the stems (Figures 1 and 2; Tables 1 to 4 ).

\section{Evaluation of the total flavonoidics antibiosis content in the mechanism of resistance of three $M$. esculenta cultivars against $C$. gloeosporioides.}

The results of the evaluation of the content of flavonoid antibiosis in the leaves and stems of plants inoculated with the inoculum of C. gloeosporioides (in $\mu \mathrm{g} / \mathrm{g}$ quercetol equivalent) are presented in figures 3 and 4 , and in tables V to VIII. It can be seen that the amounts of total flavonoid antibiosis increased steadily from the 2nd DAI to reach their maximum values by the 9th DAI for all plants of cultivars inoculated with the inoculum of
Colletotrichum gloeosporioides. From the 10th DAI onwards, the flavonoid antibiosis contained in the organs declined steadily until the 180th DAI. The histograms also showed a bell-shaped curve for each of the 3 cultivars, and showed a significant stimulation threshold and stimulation optimum $(\mathrm{F}=27.53 ; \mathrm{p}<0.05)$ following the mean comparison test. The stimulation threshold was found after 2 DIAs for all 3 cultivars studied. It was $787.65 \pm 2.85$; $452.46 \pm 4.65$ and $304.87 \pm 1.65 \mu \mathrm{g} / \mathrm{g} \mathrm{DM}$ for leaves, and $117.63 \pm 2.45 ; 87.45 \pm 3.15$ and $61.96 \pm 2.65 \mu \mathrm{g} / \mathrm{g}$ DM for stems of cultivars 9620A, TMS30572 and YACE respectively. The optimum stimulation (maximum accumulation stage) was determined according to the date from which the cassava cultivar accumulated the highest amount of total flavonoidics antibiosis in its response to aggression by $C$. gloeosporioides. Thus, this optimum value was 4303.28 \pm 4.65 ; $3273.45 \pm 2.37$ and $1986.24 \pm 4.36 \mu \mathrm{g} / \mathrm{g}$ DM for the leaves of 3 cultivars 9620A, TMS30572 and YACE (Figure 3; Tables 5 and 6).

\section{Identification of flavonoidics antibiosis by Thin Layer Chromatography (TLC)}

The TLCs of extracts from leaves and stems of plants inoculated with the inoculum of C. gloeosporioides are shown in Figures 5 B to $\mathrm{E}$ and $6 \mathrm{~B}$ to $\mathrm{E}$. Comparison of the chromatographic profiles of extracts from inoculated plants with those wounded and uninoculated (Figures $5 \mathrm{~A}$ and $6 \mathrm{~A}$ ), showed that after treatment with the fungus, (at DAI 1; 7 and 9) neosynthesized flavonoid antibiosis, fluorescent blue ( $R f$ 0.90), blue-green (Rf 0.85) and yellow-orange (Rf 0.84 and 0.88), appeared. In addition, these comparisons showed that the yellow-orange flavonoid antibiosis (Rf 0.84 and 0.88 ) present in the 7th DAI disappeared in the 9th DAI and at harvest. Two of the main flavonoidics antibiosis (orange of Rf 0.73 and green of Rf 0.80) were identified in both inoculated and control plants. 

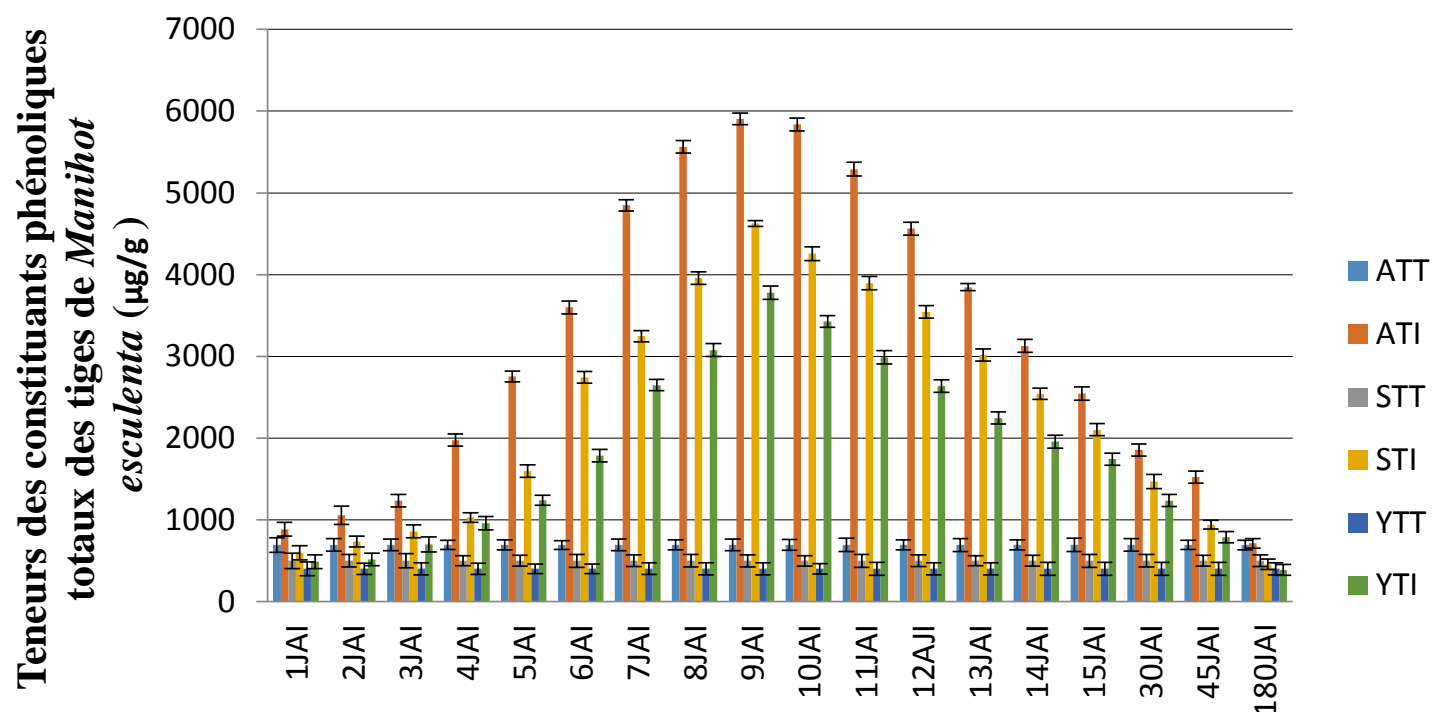

Nombre de jours après infection des cultivars de Manihot esculenta

Figure 2: Total phenolic antibiosis levels in stems (T) of inoculated (I) and uninoculated (T) Manihot esculenta cultivars (A, $\mathbf{S}$ and $\mathbf{Y})$ as a function of number of days.

DAI: day after inoculation; A: 9620A; S: TMS30572; Y: YACE; C: Controls.

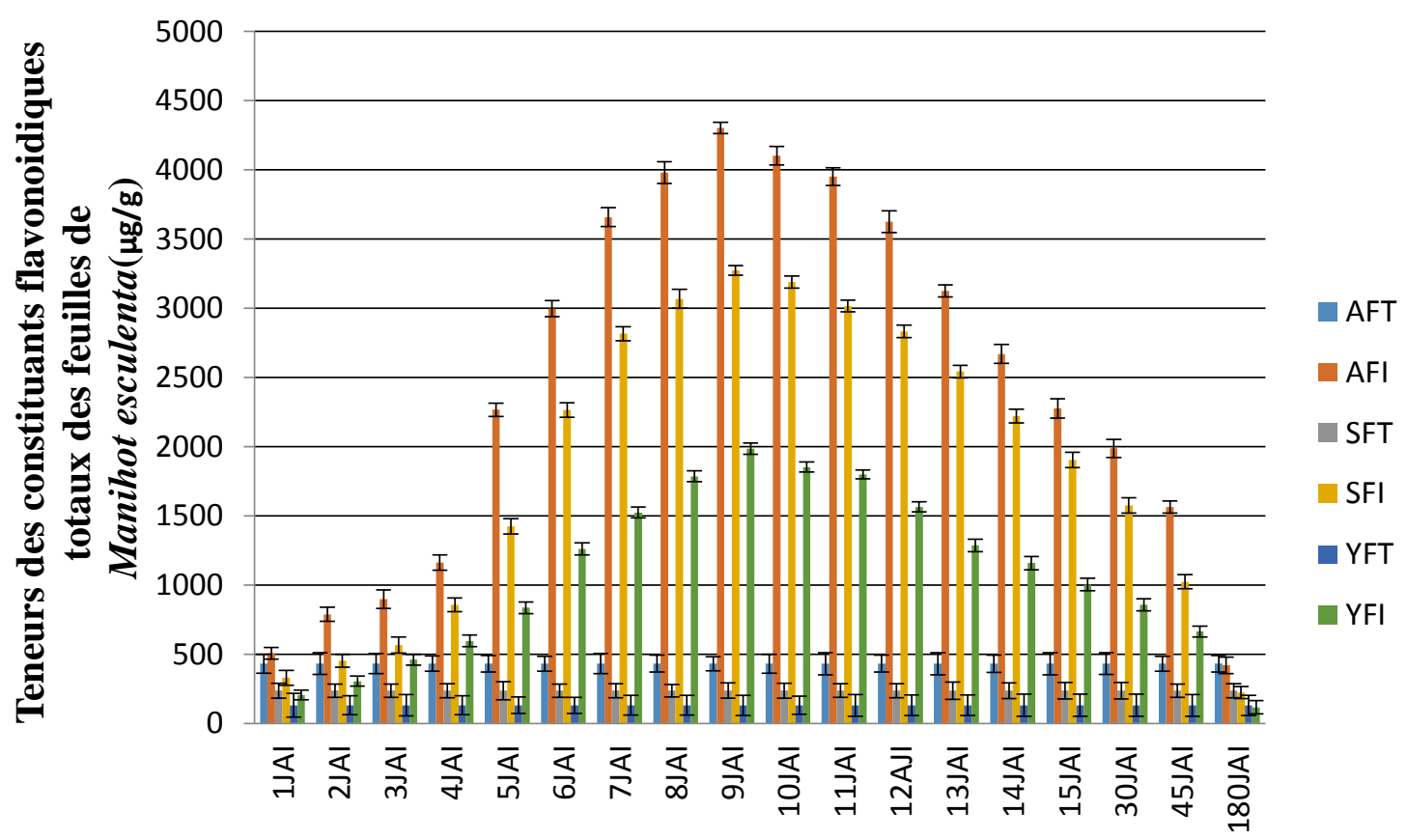

Nombre de jours après infection des cultivars de Manihot esculenta

Figure 3: Total flavonoid antibiosis levels in leaf extracts $(\mathbf{F})$ of inoculated (I) and uninoculated (T) Manihot esculenta cultivars (A, $\mathbf{S}$ and $\mathbf{Y})$ as a function of the number of days.

DAI: day after inoculation; A: 9620A; S: TMS30572; Y: YACE; T: Controls. 
K. G. BROU et al. / Int. J. Biol. Chem. Sci. 14(8): 2854-2869, 2020

Table 1: Amounts of total phenolic constituents from leaves of uninjured Manihot esculenta cultivars from 5th to 10th month after planting.

\begin{tabular}{|c|c|c|c|c|c|c|c|c|c|c|c|c|c|c|}
\hline \multirow{2}{*}{$\begin{array}{l}\text { Cultivars } \\
\text { of } M . \\
\text { esculenta }\end{array}$} & \multicolumn{14}{|c|}{ Quantity in $\mu \mathrm{g} / \mathrm{g}$ of phenolic constituents of cultivars in control plots from the 1 st day of the 5th month to the 10th month after planting } \\
\hline & 1DAP & 2DAP & 3DAP & 4DAP & 5DAP & 6DAP & 7DAP & 8DAP & 9DAP & 10DAP & 15DAP & 30DAP & 45DAP & 180DAP \\
\hline Y & $\begin{array}{l}1262,76 \pm \\
19,38\end{array}$ & $\begin{array}{l}1262, \quad 89 \\
\pm 23,17\end{array}$ & $\begin{array}{l}1260,97 \\
\pm 26,47\end{array}$ & $\begin{array}{l}1262,79 \\
\pm 16,12\end{array}$ & $\begin{array}{l}1263,01 \pm \\
15,36\end{array}$ & $\begin{array}{l}1262, \quad 79 \\
\pm 19,83\end{array}$ & $\begin{array}{l}1262,45 \\
\pm 36,04\end{array}$ & $\begin{array}{l}1262,78 \pm \\
25,36\end{array}$ & $\begin{array}{l}1261,98 \pm \\
16,25\end{array}$ & $\begin{array}{l}1263,06 \\
\pm 25,21\end{array}$ & $\begin{array}{l}1262,76 \pm \\
17,02\end{array}$ & $\begin{array}{l}1263,01 \\
\pm 15,71\end{array}$ & $\begin{array}{l}1262,77 \\
\pm 15,43\end{array}$ & $\begin{array}{l}1262,49 \\
\pm 34,17\end{array}$ \\
\hline S & $\begin{array}{l}1563,62 \pm \\
25,72\end{array}$ & $\begin{array}{l}1563,75 \pm \\
16,32\end{array}$ & $\begin{array}{l}1563,25 \\
\pm 18,49\end{array}$ & $\begin{array}{l}1562,95 \pm \\
19,86\end{array}$ & $\begin{array}{l}1563,67 \\
\pm 26,47\end{array}$ & $\begin{array}{l}1564,01 \pm \\
35,16\end{array}$ & $\begin{array}{l}1563,81 \\
\pm 26,47\end{array}$ & $\begin{array}{l}1563,29 \\
\pm 35,39\end{array}$ & $\begin{array}{l}1562,74 \\
\pm 17,83\end{array}$ & $\begin{array}{l}1563,85 \pm \\
25,76\end{array}$ & $\begin{array}{l}1562,75 \pm \\
34,05\end{array}$ & $\begin{array}{l}1563,25 \pm \\
34,75\end{array}$ & $\begin{array}{l}1561,93 \\
\pm 25,12\end{array}$ & $\begin{array}{l}1563,59 \\
\pm 21,74\end{array}$ \\
\hline A & $\begin{array}{l}1873,06 \pm \\
24,78\end{array}$ & $\begin{array}{l}1872, \quad 73 \\
\pm 25,23\end{array}$ & $\begin{array}{l}1871,99 \pm \\
11,36\end{array}$ & $\begin{array}{l}1873,13 \\
\pm 15,09\end{array}$ & $\begin{array}{l}1872,99 \\
\pm 18,71\end{array}$ & $\begin{array}{l}1873,74 \\
\pm 24,05\end{array}$ & $\begin{array}{l}1872,95 \pm \\
18,16\end{array}$ & $\begin{array}{l}1873,57 \pm \\
14,37\end{array}$ & $\begin{array}{l}1873,17 \\
\pm 15,63\end{array}$ & $\begin{array}{l}1874,04 \\
\pm 25,44\end{array}$ & $\begin{array}{l}1873,11 \\
\pm 16,25\end{array}$ & $\begin{array}{l}1872,78 \pm \\
14,36\end{array}$ & $\begin{array}{l}1873,31 \\
\pm 16,65\end{array}$ & $\begin{array}{l}1873,07 \\
\pm 15,41\end{array}$ \\
\hline
\end{tabular}

DAP: Day of the 5th month to the 10th month After Planting; Y: YACE; S: TMS30572; A: 9620A.

Table 2: Amounts of total phenolic antibiosis from leaves of cultivars of M. esculenta after injury.

\begin{tabular}{|c|c|c|c|c|c|c|c|c|c|c|c|c|c|c|}
\hline \multirow{2}{*}{$\begin{array}{l}\text { Cultivars } \\
\text { of } M \text {. } \\
\text { esculenta }\end{array}$} & \multicolumn{14}{|c|}{ Amount in $\mu \mathrm{g} / \mathrm{g}$ of total phenolic antibiotics according to the number of days (D) after (A) injury (B) of the cultivars } \\
\hline & 1DAB & 2DAB & 3DAB & 4DAB & 5DAB & 6DAB & 7DAB & 8DAB & 9DAB & 10DAB & 15DAB & 30DAB & 45DAB & 180DAB \\
\hline \multirow{3}{*}{$\mathrm{Y}$} & $1271,23 \pm$ & 1321,43 & 1385,04 & 1402,09 & 1361,46 & 1352,83 & 1349,75 & 1350,81 & 1353,84 & 1344,76 & $1338,03 \pm$ & $1322,05 \pm$ & 1317,51 & 1261,81 \\
\hline & 11,84 & $\pm 13,25$ & $\pm 15,05$ & $\pm 17,01$ & $\pm 16,23$ & $\pm 16,89$ & $\pm 15,25$ & $\pm 14,33$ & $\pm 13,21$ & $\pm 15,72$ & 16,22 & 14,71 & $\pm 16,02$ & $\pm 15,42$ \\
\hline & $1564,52 \pm$ & $1597,64 \pm$ & 1654,42 & $1701,01 \pm$ & 1695,42 & 1685,72 & 1681,48 & 1680,25 & 1675,27 & 1670,01 & $1661,43 \pm$ & $1631,72 \pm$ & 1614,12 & 1562,89 \\
\hline \multirow[t]{2}{*}{$S$} & 16,01 & 15,07 & $\pm 17,43$ & 14,37 & $\pm 12,07$ & $\pm 18,01$ & $\pm 17,05$ & $\pm 16,73$ & $\pm 13,17$ & $\pm 14,81$ & 17,21 & 12,86 & $\pm 17,63$ & $\pm 14,46$ \\
\hline & 1887,81 & 1898,93 & 1920,98 & 1984,77 & $1971,04 \pm$ & 1965,41 & 1963,95 & 1960,78 & 1957,51 & 1881,01 & 1878,15 & $1875,68 \pm$ & 1873,21 & 1873,97 \\
\hline A & $\pm 15,71$ & $\pm 16,07$ & $\pm 15,14$ & $\pm 16,21$ & 14,23 & $\pm 14,12$ & $\pm 16,73$ & $\pm 13,05$ & $\pm 16,34$ & $\pm 14,01$ & $\pm 15,02$ & 13,74 & $\pm 14,15$ & $\pm 17,12$ \\
\hline
\end{tabular}


Table 3: Amounts of total phenolic antibiosis from stems of uninjured M. esculenta cultivars from 5th to 10th month after planting.

\begin{tabular}{|c|c|c|c|c|c|c|c|c|c|c|c|c|c|c|}
\hline \multirow{2}{*}{$\begin{array}{l}\text { Cultivars } \\
\text { of } M \text {. } \\
\text { esculenta }\end{array}$} & \multicolumn{14}{|c|}{ Quantity in $\mu \mathrm{g} / \mathrm{g}$ of total phenolic antibiosis of cultivars in control plots from the 1 st day of the 5 th month to the 10 th month after planting } \\
\hline & 1DAP & 2DAP & 3DAP & 4DAP & 5DAP & 6DAP & 7DAP & 8DAP & 9DAP & 10DAP & 15DAP & 30DAP & 45DAP & 180DAP \\
\hline \multirow{3}{*}{$\mathrm{Y}$} & 401,01 & 400,85 & 401,15 & 402,05 & 400,98 & 401,21 & 402,02 & 401,27 & 401,12 & 401,35 & 401,26 & 400,95 & 402,05 & 401,22 \\
\hline & $\pm 11,31$ & $\pm 18,23$ & $\pm 10,01$ & $\pm 21,41$ & $\pm 16,53$ & $\pm 12,43$ & $\pm 22,02$ & $\pm 13,07$ & $\pm 10,15$ & $\pm 12,57$ & $\pm 10,23$ & $\pm 11,65$ & $\pm 22,05$ & $\pm 13,04$ \\
\hline & 499,65 & 498,82 & 499,84 & 500,03 & 499,93 & 499,78 & 499,89 & 500,08 & 498,89 & 499,83 & 499,84 & 499,63 & 500,03 & 499,81 \\
\hline \multirow[t]{2}{*}{ S } & $\pm 11,64$ & $\pm 12,41$ & $\pm 10,06$ & $\pm 13,34$ & $\pm 18,36$ & $\pm 14,68$ & $\pm 13,36$ & $\pm 22,02$ & $\pm 16,74$ & $\pm 17,63$ & $\pm 15,85$ & $\pm 19,06$ & $\pm 13,58$ & $\pm 17,04$ \\
\hline & 693,75 & 692,95 & 693,53 & 693,56 & 694,06 & 693,18 & 693,64 & 692,95 & 693,45 & 693,47 & 694,07 & 692,91 & 694,13 & 693,74 \\
\hline A & $\pm 10,22$ & $\pm 9,75$ & $\pm 10,45$ & $\pm 17,06$ & $\pm 23,85$ & $\pm 11,27$ & $\pm 12,54$ & $\pm 19,74$ & $\pm 13,25$ & $\pm 11,38$ & $\pm 17,89$ & $\pm 24,45$ & $\pm 13,11$ & $\pm 12,41$ \\
\hline
\end{tabular}

DAP: Day of the 5th month to the 10th month After Planting; Y: YACE; S: TMS30572; A: 9620A

Table 4: Amounts of total phenolic antibiosis from stems of cultivars of M. esculenta after injury.

\begin{tabular}{|c|c|c|c|c|c|c|c|c|c|c|c|c|c|c|}
\hline \multirow{2}{*}{$\begin{array}{l}\text { Cultivars } \\
\text { of } M . \\
\text { esculenta }\end{array}$} & \multicolumn{14}{|c|}{ Amount in $\mu \mathrm{g} / \mathrm{g}$ of total phenolic antibiosis according to the number of days (D) after (A) injury (B) of the cultivars } \\
\hline & 1DAB & 2DAB & 3DAB & 4DAB & 5DAB & 6DAB & 7DAB & 8DAB & 9DAB & 10DAB & 15DAB & 30DAB & 45DAB & 180DAB \\
\hline Y & $\begin{array}{l}407,33 \\
\pm 9,76\end{array}$ & $\begin{array}{l}422,63 \\
\pm 11,07\end{array}$ & $\begin{array}{l}458,14 \\
\pm 11,21\end{array}$ & $\begin{array}{l}461,23 \\
\pm 13,44\end{array}$ & $\begin{array}{l}459,99 \\
\pm 14,01\end{array}$ & $\begin{array}{l}460,01 \\
\pm 10,09\end{array}$ & $\begin{array}{l}455,71 \\
\pm 13,46\end{array}$ & $\begin{array}{l}455,07 \\
\pm 11,82\end{array}$ & $\begin{array}{l}453,89 \\
\pm 13,19\end{array}$ & $\begin{array}{l}454,01 \\
\pm 14,03\end{array}$ & $\begin{array}{l}448,12 \\
\pm 14,05\end{array}$ & $\begin{array}{l}439,07 \\
\pm 13,74\end{array}$ & $\begin{array}{l}432,33 \\
\pm 11,63\end{array}$ & $\begin{array}{l}404,29 \\
\pm 15,44\end{array}$ \\
\hline$S$ & $\begin{array}{l}511,33 \\
\pm 10,68\end{array}$ & $\begin{array}{l}544,52 \\
\pm 13,23\end{array}$ & $\begin{array}{l}568,11 \\
\pm 12,75\end{array}$ & $\begin{array}{l}573,23 \\
\pm 11,63\end{array}$ & $\begin{array}{l}570,12 \\
\pm 14,08\end{array}$ & $\begin{array}{l}568,44 \\
\pm 13,77\end{array}$ & $\begin{array}{l}562,76 \\
\pm 12,01\end{array}$ & $\begin{array}{l}560,21 \\
\pm 14,39\end{array}$ & $\begin{array}{l}551,68 \\
\pm 16,13\end{array}$ & $\begin{array}{l}548,32 \\
\pm 14,89\end{array}$ & $\begin{array}{l}540,71 \\
\pm 13,71\end{array}$ & $\begin{array}{l}531,43 \\
\pm 11,59\end{array}$ & $\begin{array}{l}520,03 \\
\pm 14,29\end{array}$ & $\begin{array}{l}502,69 \\
\pm 17,13\end{array}$ \\
\hline $\mathrm{A}$ & $\begin{array}{l}719,73 \\
\pm 13,43\end{array}$ & $\begin{array}{l}778,49 \\
\pm 12,11\end{array}$ & $\begin{array}{l}806,17 \\
\pm 13,77\end{array}$ & $\begin{array}{l}862,06 \\
\pm 14,13\end{array}$ & $\begin{array}{l}852,18 \\
\pm 13,66\end{array}$ & $\begin{array}{l}849,92 \\
\pm 12,48\end{array}$ & $\begin{array}{l}833,05 \\
\pm 10,01\end{array}$ & $\begin{array}{l}831,69 \\
\pm 13,67\end{array}$ & $\begin{array}{l}825,23 \\
\pm 12,91\end{array}$ & $\begin{array}{l}792,44 \\
\pm 13,19\end{array}$ & $\begin{array}{l}779,87 \\
\pm 12,13\end{array}$ & $\begin{array}{l}751,05 \\
\pm 14,62\end{array}$ & $\begin{array}{l}731,58 \\
\pm 10,25\end{array}$ & $\begin{array}{l}703,74 \\
\pm 13,59\end{array}$ \\
\hline
\end{tabular}

DAB: days (D) after (A) injury (B); Y: YACE; S: TMS30572; A: 9620A. 
Table 5: Quantities of total flavonoid antibiosis of leaves (5th to 10th month after planting) of uninjured M. esculenta plants.

\begin{tabular}{|c|c|c|c|c|c|c|c|c|c|c|c|c|c|c|}
\hline \multirow{2}{*}{$\begin{array}{l}\text { Cultivars } \\
\text { of } M \text {. } \\
\text { esculenta }\end{array}$} & \multicolumn{14}{|c|}{ Amount in $\mu \mathrm{g} / \mathrm{g}$ of flavonoid constituents of cultivars in control plots from the 5 th month to the 10 th month after planting } \\
\hline & 1DAP & 2DAP & 3DAP & 4DAP & 5DAP & 6DAP & 7DAP & 8DAP & 9DAP & 10DAP & 15DAP & 30DAP & 45DAP & 180DAP \\
\hline $\mathrm{Y}$ & $\begin{array}{l}130,69 \\
\pm 15,31\end{array}$ & $\begin{array}{l}130,68 \\
\pm 14,25\end{array}$ & $\begin{array}{l}130,98 \\
\pm 16,45\end{array}$ & $\begin{array}{l}131,11 \\
\pm 14,12\end{array}$ & $\begin{array}{l}130,49 \\
\pm 15,26\end{array}$ & $\begin{array}{l}130,41 \\
\pm 14,24\end{array}$ & $\begin{array}{l}129,95 \\
\pm 16,25\end{array}$ & $\begin{array}{l}130,67 \\
\pm 15,21\end{array}$ & $\begin{array}{l}128,97 \\
\pm 14,59\end{array}$ & $\begin{array}{l}130,41 \\
\pm 15,02\end{array}$ & $\begin{array}{l}131,11 \\
\pm 13,42\end{array}$ & $\begin{array}{l}130,65 \\
\pm 12,39\end{array}$ & $\begin{array}{l}131,21 \\
\pm 14,28\end{array}$ & $\begin{array}{l}130,67 \\
\pm 16,43\end{array}$ \\
\hline$S$ & $\begin{array}{l}236,04 \\
\pm 15,42\end{array}$ & $\begin{array}{l}236,35 \\
\pm 16,18\end{array}$ & $\begin{array}{l}236,14 \\
\pm 17,07\end{array}$ & $\begin{array}{l}237,48 \\
\pm 16,46\end{array}$ & $\begin{array}{l}236,67 \\
\pm 15,41\end{array}$ & $\begin{array}{l}235,95 \\
\pm 18,36\end{array}$ & $\begin{array}{l}236,03 \\
\pm 16,18\end{array}$ & $\begin{array}{l}237,01 \\
\pm 17,34\end{array}$ & $\begin{array}{l}235,97 \\
\pm 15,56\end{array}$ & $\begin{array}{l}236,81 \\
\pm 18,55\end{array}$ & $\begin{array}{l}236,75 \\
\pm 17,45\end{array}$ & $\begin{array}{l}237,45 \\
\pm 18,65\end{array}$ & $\begin{array}{l}235,94 \\
\pm 17,42\end{array}$ & $\begin{array}{l}236,49 \\
\pm 18,92\end{array}$ \\
\hline A & $\begin{array}{l}430,85 \\
\pm 23,26\end{array}$ & $\begin{array}{l}430,82 \\
\pm 24,15\end{array}$ & $\begin{array}{l}430,74 \\
\pm 23,32\end{array}$ & $\begin{array}{l}429,99 \\
\pm 24,65\end{array}$ & $\begin{array}{l}431,05 \\
\pm 22,21\end{array}$ & $\begin{array}{l}430,27 \\
\pm 24,59\end{array}$ & $\begin{array}{l}431,25 \\
\pm 24,25\end{array}$ & $\begin{array}{l}430,81 \\
\pm 25,67\end{array}$ & $\begin{array}{l}430,28 \\
\pm 23,63\end{array}$ & $\begin{array}{l}428,92 \\
\pm 22,54\end{array}$ & $\begin{array}{l}430,26 \\
\pm 26,25\end{array}$ & $\begin{array}{l}430,87 \\
\pm 24,36\end{array}$ & $\begin{array}{l}431,13 \\
\pm 20,65\end{array}$ & $\begin{array}{l}430,21 \\
\pm 15,41\end{array}$ \\
\hline
\end{tabular}

DAP: DAP: Day of the 5th month to the 10th month After Planting; Y: YACE; S: TMS30572; A: 9620A.

Table 6: Amounts of total flavonoid antibiosis from leaves of $M$. esculenta cultivars after injury.

\begin{tabular}{|c|c|c|c|c|c|c|c|c|c|c|c|c|c|c|}
\hline \multirow{2}{*}{$\begin{array}{l}\text { Cultivars } \\
\text { of } M \text {. } \\
\text { esculenta }\end{array}$} & \multicolumn{14}{|c|}{ Amount in $\mu \mathrm{g} / \mathrm{g}$ of flavonoid antibiosis according to the number of days (D) after (A) injury (B) of the cultivars } \\
\hline & 1DAB & 2DAB & 3DAB & 4DAB & 5DAB & 6DAB & 7DAB & 8DAB & 9DAB & 10DAB & 15DAB & 30DAB & 45DAB & 180DAB \\
\hline & 138,94 & 157,76 & 176,84 & 182,41 & 181,66 & 181,49 & 179,93 & 164,38 & 163,94 & 164,06 & 161,63 & 151,51 & 142,73 & 133,12 \\
\hline $\mathrm{Y}$ & $\pm 6,98$ & $\pm 9,36$ & $\pm 10,13$ & $\pm 14,35$ & $\pm 13,04$ & $\pm 10,52$ & $\pm 13,43$ & $\pm 11,74$ & $\pm 10,66$ & $\pm 9,02$ & $\pm 11,02$ & $\pm 12,31$ & $\pm 15,01$ & $\pm 11,01$ \\
\hline & 243,52 & 262,73 & 284,37 & 291,12 & 289,44 & 288,85 & 285,29 & 281,72 & 269,74 & 265,49 & 263,84 & 253,62 & 250,13 & 238,75 \\
\hline $\mathrm{S}$ & $\pm 7,12$ & $\pm 5,73$ & $\pm 8,12$ & $\pm 13,01$ & $\pm 10,71$ & $\pm 14,01$ & $\pm 14,12$ & $\pm 13,36$ & $\pm 12,11$ & $\pm 11,42$ & $\pm 10,24$ & $\pm 11,31$ & $\pm 10,12$ & $\pm 14,83$ \\
\hline A & $\begin{array}{c}436,18 \\
\pm 7,39\end{array}$ & $\begin{array}{r}443,88 \\
\pm 10,01\end{array}$ & $\begin{array}{c}458,87 \\
\pm 9,47\end{array}$ & $\begin{array}{l}467,96 \\
\pm 12,78\end{array}$ & $\begin{array}{l}465,02 \\
\pm 10,14\end{array}$ & $\begin{array}{c}463,41 \\
\pm 9,05\end{array}$ & $\begin{array}{c}459,95 \\
\pm 9,74\end{array}$ & $\begin{array}{l}452,87 \\
\pm 12,63\end{array}$ & $\begin{array}{l}451,63 \\
\pm 11,12\end{array}$ & $\begin{array}{l}450,71 \\
\pm 10,03\end{array}$ & $\begin{array}{l}448,33 \\
\pm 11,01\end{array}$ & $\begin{array}{l}445,02 \\
\pm 13,66\end{array}$ & $\begin{array}{l}440,71 \\
\pm 12,25\end{array}$ & $\begin{array}{r}435,24 \\
\pm 13,62\end{array}$ \\
\hline
\end{tabular}

DAB: days (D) after (A) injury (B); Y: YACE; S: TMS30572; A: 9620A. 
Table 7: Quantities of total flavonoid constituents from stems of uninjured Manihot esculenta cultivars from 5th to 10th month after planting.

\begin{tabular}{|c|c|c|c|c|c|c|c|c|c|c|c|c|c|c|}
\hline \multirow{2}{*}{$\begin{array}{l}\text { Cultivars } \\
\text { of } M . \\
\text { esculenta }\end{array}$} & \multicolumn{14}{|c|}{ Amount in $\mu \mathrm{g} / \mathrm{g}$ of flavonoid constituents of cultivars in control plots from the 5th month to the 10th month after planting } \\
\hline & 1DAP & 2DAP & 3DAP & 4DAP & 5DAP & 6DAP & 7DAP & 8DAP & 9DAP & 10DAP & 15DAP & 30DAP & 45DAP & 180DAP \\
\hline Y & $\begin{array}{l}31,46 \\
\pm 7,35\end{array}$ & $\begin{array}{l}31,62 \\
\pm 9,23\end{array}$ & $\begin{array}{l}30,89 \\
\pm 8,36\end{array}$ & $\begin{array}{l}31,46 \\
\pm 7,12\end{array}$ & $\begin{array}{l}32,07 \\
\pm 9,26\end{array}$ & $\begin{array}{l}31,61 \\
\pm 8,24\end{array}$ & $\begin{array}{l}32,04 \\
\pm 6,23\end{array}$ & $\begin{array}{l}31,47 \\
\pm 8,21\end{array}$ & $\begin{array}{l}30,85 \\
\pm 9,59\end{array}$ & $\begin{array}{l}31,66 \\
\pm 8,28\end{array}$ & $\begin{array}{l}31,36 \\
\pm 9,45\end{array}$ & $\begin{array}{l}32,16 \\
\pm 8,39\end{array}$ & $\begin{array}{l}31,25 \\
\pm 7,28\end{array}$ & $\begin{array}{l}31,45 \\
\pm 6,42\end{array}$ \\
\hline S & $\begin{array}{l}44,65 \\
\pm 10,54\end{array}$ & $\begin{array}{l}45,02 \\
\pm 9,46\end{array}$ & $\begin{array}{l}44,14 \\
\pm 10,26\end{array}$ & $\begin{array}{l}44,31 \\
\pm 9,42\end{array}$ & $\begin{array}{l}43,92 \\
\pm 10,63\end{array}$ & $\begin{array}{l}44,48 \\
\pm 10,38\end{array}$ & $\begin{array}{l}43,96 \\
\pm 9,16\end{array}$ & $\begin{array}{l}44,68 \\
\pm 7,34\end{array}$ & $\begin{array}{l}44,65 \\
\pm 7,54\end{array}$ & $\begin{array}{l}45,03 \\
\pm 9,15\end{array}$ & $\begin{array}{l}44,64 \\
\pm 13,41\end{array}$ & $\begin{array}{l}44,66 \\
\pm 10,63\end{array}$ & $\begin{array}{l}45,03 \\
\pm 12,18\end{array}$ & $\begin{array}{l}44,64 \\
\pm 10,91\end{array}$ \\
\hline A & $\begin{array}{l}71,16 \\
\pm 6,26\end{array}$ & $\begin{array}{l}71,52 \\
\pm 7,15\end{array}$ & $\begin{array}{l}71,38 \\
\pm 8,32\end{array}$ & $\begin{array}{l}71,63 \\
\pm 8,65\end{array}$ & $\begin{array}{l}70,96 \\
\pm 7,61\end{array}$ & $\begin{array}{l}70,88 \\
\pm 9,58\end{array}$ & $\begin{array}{l}72,09 \\
\pm 9,24\end{array}$ & $\begin{array}{l}71,15 \\
\pm 9,65\end{array}$ & $\begin{array}{l}71,33 \\
\pm 7,63\end{array}$ & $\begin{array}{l}70,99 \\
\pm 10,64\end{array}$ & $\begin{array}{l}71,17 \\
\pm 7,53\end{array}$ & $\begin{array}{l}71,11 \\
\pm 8,46\end{array}$ & $\begin{array}{l}72,03 \\
\pm 10,25\end{array}$ & $\begin{array}{l}71,14 \\
\pm 10,35\end{array}$ \\
\hline
\end{tabular}

DAP: DAP: Day of the 5th month to the 10th month After Planting; Y: YACE; S: TMS30572; A: 9620A.

Table 8: Quantities of total flavonoid antibiosis of the stems of cultivars of M. esculenta after injury.

\begin{tabular}{|c|c|c|c|c|c|c|c|c|c|c|c|c|c|c|}
\hline \multirow{2}{*}{$\begin{array}{l}\text { Cultivars } \\
\text { of } M \text {. } \\
\text { esculenta }\end{array}$} & \multicolumn{14}{|c|}{ Amount in $\mu \mathrm{g} / \mathrm{g}$ of flavonoid antibiosis according to the number of days (D) after (A) injury (B) of the cultivars } \\
\hline & $1 \mathrm{DAB}$ & $2 \mathrm{DAB}$ & $3 \mathrm{DAB}$ & 4DAB & $5 \mathrm{DAB}$ & $6 \mathrm{DAB}$ & $7 \mathrm{DAB}$ & $8 \mathrm{DAB}$ & $9 \mathrm{DAB}$ & $10 \mathrm{DAB}$ & $15 \mathrm{DAB}$ & $30 \mathrm{DAB}$ & $45 \mathrm{DAB}$ & $180 \mathrm{DAB}$ \\
\hline & 35,51 & 332,39 & 41,75 & 42,33 & 41,79 & 41,55 & 41,35 & 41,17 & 41,05 & 40,83 & 40,65 & 39,74 & 39,05 & 33,17 \\
\hline $\mathrm{Y}$ & $\pm 10,63$ & $\pm 12,23$ & $\pm 11,61$ & $\pm 8,53$ & $\pm 10,11$ & $\pm 10,13$ & $\pm 13,12$ & $\pm 11,27$ & $\pm 10,52$ & $\pm 8,17$ & $\pm 9,05$ & $\pm 10,25$ & $\pm 10,15$ & $\pm 10,65$ \\
\hline$S$ & $\begin{array}{c}49,85 \pm 11 \\
59\end{array}$ & $\begin{array}{c}50,59 \\
\pm 10,11 \\
\end{array}$ & $\begin{array}{c}52,31 \\
\pm 11,41 \\
\end{array}$ & $\begin{array}{l}53,39 \\
\pm 7,18\end{array}$ & $\begin{array}{l}53,02 \\
\pm 9,36\end{array}$ & $\begin{array}{c}52,78 \\
\pm 11,56 \\
\end{array}$ & $\begin{array}{c}52,69 \\
\pm 10,44 \\
\end{array}$ & $\begin{array}{c}52,48 \\
\pm 13,41 \\
\end{array}$ & $\begin{array}{c}52,44 \\
\pm 12,36 \\
\end{array}$ & $\begin{array}{c}52,39 \\
\pm 10,23 \\
\end{array}$ & $\begin{array}{c}52,04 \\
\pm 10,15 \\
\end{array}$ & $\begin{array}{c}51,96 \\
\pm 13,06 \\
\end{array}$ & $\begin{array}{c}51,03 \\
\pm 11,38 \\
\end{array}$ & $\begin{array}{c}47,41 \\
\pm 11,32 \\
\end{array}$ \\
\hline A & $\begin{array}{c}74,09 \\
\pm 10,89\end{array}$ & $\begin{array}{l}76,18 \\
\pm 8,41\end{array}$ & $\begin{array}{c}78,04 \\
\pm 10,45\end{array}$ & $\begin{array}{c}79,47 \\
\pm 10,36\end{array}$ & $\begin{array}{c}79,36 \\
\pm 13,59\end{array}$ & $\begin{array}{c}78,88 \\
\pm 12,25\end{array}$ & $\begin{array}{c}78,19 \\
\pm 10,14\end{array}$ & $\begin{array}{c}78,01 \\
\pm 11,14\end{array}$ & $\begin{array}{c}77,03 \\
\pm 12,65\end{array}$ & $\begin{array}{c}77,02 \\
\pm 13,48\end{array}$ & $\begin{array}{c}76,97 \\
\pm 10,09\end{array}$ & $\begin{array}{c}76,81 \\
\pm 10,31\end{array}$ & $\begin{array}{c}76,13 \\
\pm 12,21\end{array}$ & $\begin{array}{c}72,49 \\
\pm 10,72\end{array}$ \\
\hline
\end{tabular}




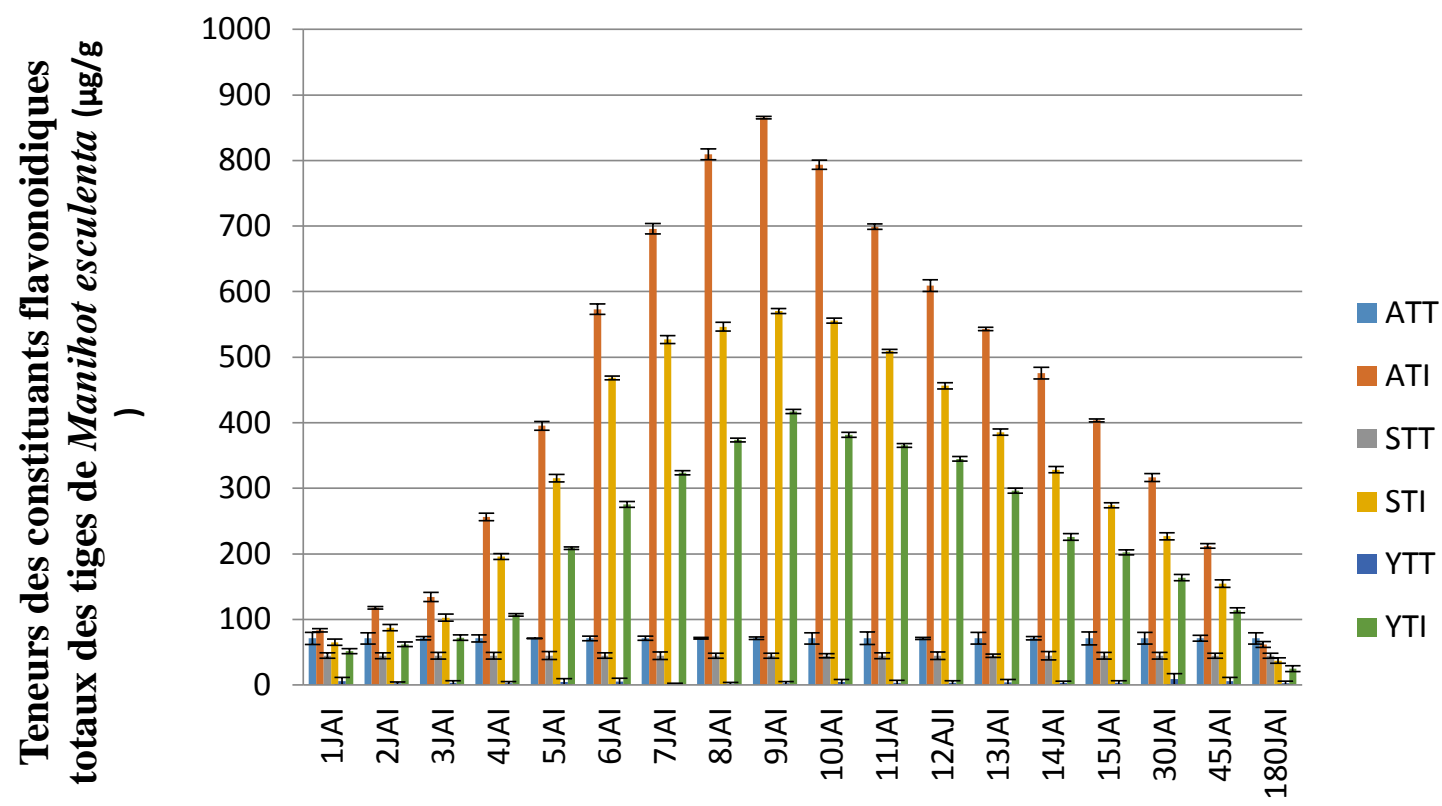

\section{Nombre de jours après infection des cultivars de Manihot esculenta}

Figure 4: Total flavonoid antibiosis levels in stem (T) extracts of inoculated (I) and uninoculated (T) Manihot esculenta cultivars $(\mathbf{A}, \mathbf{S}$ and $\mathbf{Y})$ as a function of the number of days.

DAI: day after inoculation; A: 9620A; S: TMS30572; Y: YACE; T: Controls.

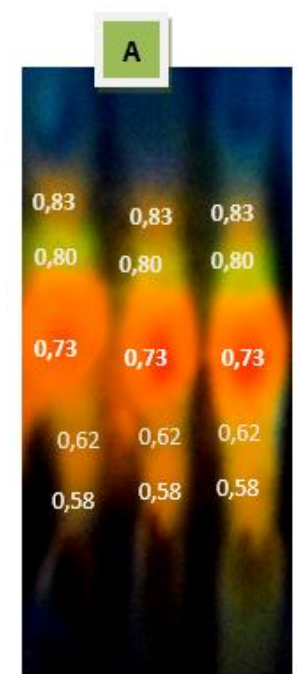

AFT SFT YFT

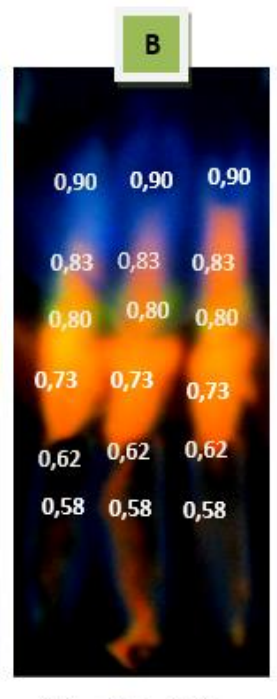

AFI SFI YFI

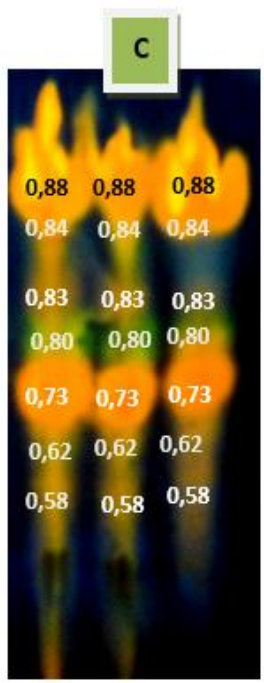

AFI SFI YFI

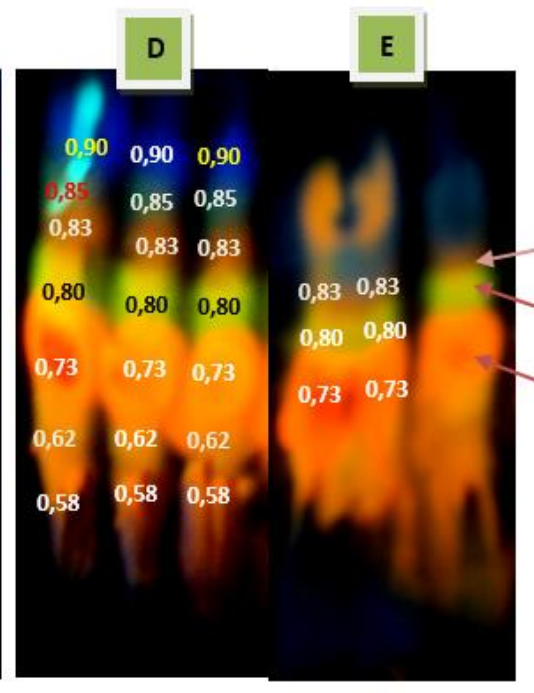

AFI SFI YFI AFI SFI YFI

\section{0,90}

0,88

0,85

0,84

0,83

0,80

0,73

0,62

0,58

Rf

Figure 5: Comparative Thin Layer Chromatography of flavonoid antibiosis of leaves (F) of cultivars A, S and Y revealed by Neu reagent and viewed under UV light at $366 \mathrm{~nm}$.

A: antibiosis of leaves of control (T) plants (F); B: antibiosis of leaves of plants inoculated at 1 Day After Inoculation (DAI); C: antibiosis of leaves of plants inoculated at 7 DAI; D: antibiosis of leaves of plants inoculated at the stage of maximum flavonoid accumulation (9 DAI); E: antibiosis at harvest stage at $180 \mathrm{DAI}$. 


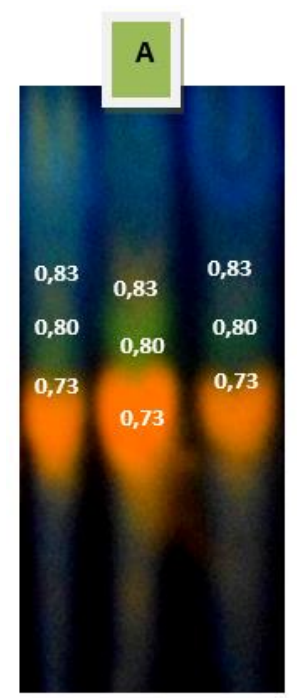

ATT STT YTT

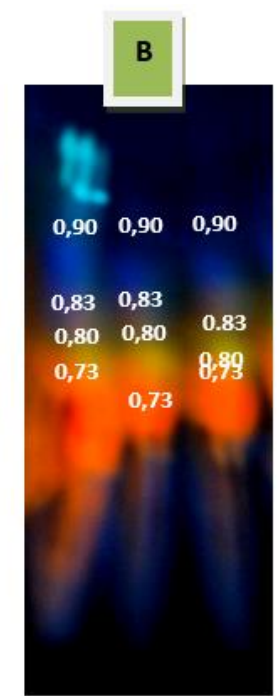

ATI STI YTI

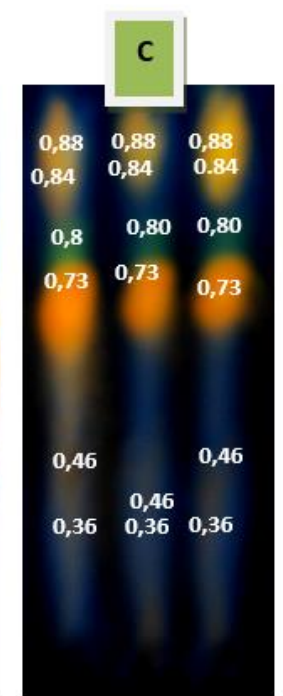

ATI STI YTI

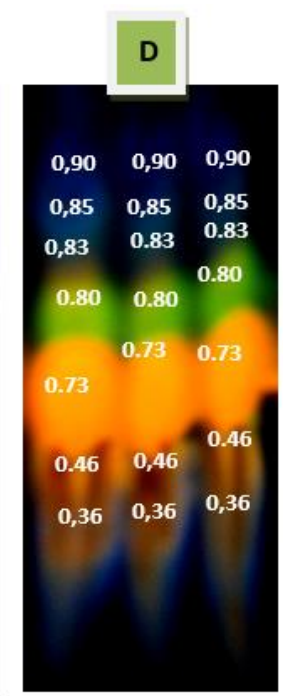

ATI STI YTI

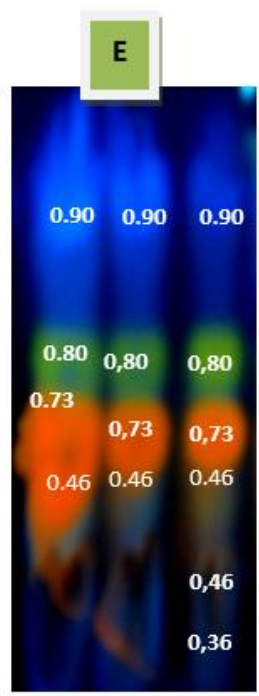

ATI STI YTI

Figure 6: Comparative Thin Layer Chromatography of flavonoid antibiosis of stems ( $T$ ) of cultivars A, S and Y revealed by Neu reagent and visualized under UV light at $366 \mathrm{~nm}$.

A: antibiosis of stems (T) of control plants (T); B: antibiosis of stems (T) of plants inoculated at 1 Day After Inoculation (DAI); C: antibiosis of stems (T) of plants inoculated at 7 DAI; D: antibiosis of stems (T) of plants inoculated at the stage of maximum flavonoid accumulation (9 DAI); E: antibiosis at harvest stage at $180 \mathrm{DAI}$.

\section{DISCUSSION}

The comparative study of phenolic antibiosis and particularly flavonoid antibiosis in healthy plants inoculated with $C$. gloeosporioides showed that the presence of this pathogen induced an increase in the synthesis of phenolic antibiosis. This increase is general in all infected plants but with a variable amplitude depending on cultivars and organs. Stimulation of the synthesis of these constituents, initiated after inoculation of the pathogen, increased steadily with the contact time of the plant with the pathogen to reach an optimum at the 9th day after inoculation (9DAI). Beyond this period, the levels of phenolic and flavonoid antibiosis decrease and reach their minimum values. Stimulation was early in all cultivars. It started in the 2nd DAI and reached its maximum value in the 9th DAI. At this date, the leaves of cultivar A accumulated 5 times their phenol content and 8.51 times this content on the stems. On the other hand, the leaves of cultivar $\mathbf{S}$ accumulated 4.22 times the basic phenol content and the stems concentrated 9.25 times. The reference cultivar $\mathbf{Y}$ accumulated 3.32 and
7.22 times the phenol content for the leaves and stems respectively. Phenol accumulations in A and $\mathbf{S}$ are higher than those of the reference cultivar Y. Flavonoid antibiosis accumulation was also high. It was 9.99 to 15.2 times higher depending on cultivar and organs. This concomitant increase in phenolic and flavonoid antibiosis would result from the fact that most phenolic antibiosis whose flavonoids are derived from a common precursor which is $\mathrm{p}$ coumaric acid. The latter results from the activity of phenylalanine ammonia-lyase (PAL) and tyrosine ammonia-lyase (TAL). Activation of these enzymes has been observed during elicitation of Manihot esculenta cells using salicylic acid (Dogbo et al., 2012) and infection of Camellia oleifera by Colletotrichum gloeosporioides (Xinzhang et al., 2012).

The synthesis of phenolic and flavonoidic antibiosis was early in all cultivars and organs. This very rapid accumulation of these constituents could be explained by their involvement in plant defense mechanisms (Broeckling et al., 2005; Suzuki et al., 2005; Naoumkina et al., 2007; Farag et al., 2009; 
Mancilla et al., 2009). Concerning flavonoids in particular, Chen et al. (2007), Crawford et al. (2004) and Calatayud et al. (2011) found that resistance of cultivars of Carmellia oleifera and Lupinus angustifolius correlated with rapid and intense flavonoid production. In the latter species, the amounts of flavonoid antibiosis accumulated in the leaves after 7 days of contamination by Colletotrichum lupinus had been 50 times higher than in the control (Muth et al., 2009; Wojakwoska et al., 2013).

The synthesis of secondary metabolites, particularly phenolic and flavonoid antibiosis, increased with the time of contact with the pathogen. Indeed, according to Masella et al. (2005), Farag et al (2008) and Schmitt and Dirsch (2009) an accumulation of these compounds in order to assume physiological defense functions that are recognized to them is stimulated after the aggression of the plant by a pathogen. The increase in the observed accumulation time of flavonoids in both leaves and stems after fungal infection is thought to be related, on the one hand, to the contact time Manihot esculenta-Colletotrichum gloeosporioides and, on the other hand, to the transduction of the elicitor signal to initiate the synthesis of defense substances (Lozovaya et al., 2004; Grotewold, 2006; Farag et al., 2008; Schliemann et al., 2006; Bednarek and Osbourn, 2009; Jasin'ski et al., 2009.

\section{Conclusion}

The study of the defense reaction of $M$. esculenta against $C$. gloeosporioides has shown that inoculation of cassava cultivars with this pathogen induced an early reaction of antibiosis of these 2 DAI. In addition, it has induced a maximal and generalized accumulation of phenolic antibiosis and flavonoid antibiosis 9 DAI. The generalized accumulation of these antibiosis was stronger in cultivar A. But all cultivars showed the same stimulation threshold and the same maximum accumulation times. However, during the expression of this systemic defense, the inoculated cultivars have, over time, accumulated various types of flavonoid antibiosis. This flavonoid antibiosis has played the role of phenolic resistance markers in the defense reaction of cultivars of $M$. esculenta against $C$. gloeosporioides.
This study approach, through the parameters addressed, made it possible to discriminate the level of resistance of the cultivars and can therefore be used as a complementary tool to classics tests for cultivar selection.

\section{COMPETING INTERESTS}

The authors declare that they have no competing interests.

\section{AUTHORS' CONTRIBUTIONS}

BKG carried out the work, collected the data and wrote the manuscript. MJLA and DS contributed to the evaluation of flavonoïd antibiosis. ZGP participated in the protocol of C. gloeosporioides inoculum production. MBJA and DDO supervised the work. KKN and BYA put their respective laboratories at our disposal to carry out the work. All these coauthors have read and validated the results of the work.

\section{ACKNOWLEDGMENTS}

Thanks to the technicians of the laboratory of the Physio / Phytopathology Unit of the Central Biotechnology Laboratory and those of the CNRA roots and tubers program.

\section{REFERENCES}

Adhikari TB, Balaji B, Breeden J, Goodwin SB. 2007. Resistance of wheat to Mycosphaerella

graminicola involves early and late peaks of gene expression. Physiol. And Mol. Plant. Pathol., $\quad$ 71: 55-68: www.sciencedirect.com

Akpingny KLD, Koulou NY, Okou WCA. 2017. Fiche technicoéconomique du MANIOC. ANADER, Direction d'Appui aux Filières Agricoles.

Agence Nationale d'Appui au Développement Rural (ANADER). 2017. Direction d'Appui aux Filières Agricoles. ANADER, Côte d'Ivoire.

Ambang Z, Akoa A, Bekolo N, Nantia J, Nyobe L, Ongono YSB. 2007. Tolérance de quelques cultivars de manioc (manihot esculenta crantz) et de l'espece sauvage (manihot glaziovii) à la mosaïque virale africaine et à la cercosporiose du manioc. Tropicultura, 25(3): 140-145. 
Bednarek P, Osbourn A. 2009. Plant-Microbe interactions: chemical diversity in plant defense. Science, 324: 746-748: DOI: 101126/science.1171661

Benhamou N. 2009. La Résistance Chez les Plantes: Principes de la Stratégie Défensive et Applications Agronomiques. Éditions TEC \& DOC-Lavoisier : Paris.

Benkiki N. 2006. Etude phytochimique des plantes médicinales Algériennes: Ruta montana, Matricaria pubescens et Hypericum perfotum. Thèse de doctorat d'Etat, Univ. d'Algerie, Algerie, 198 p.

Broeckling CD, Huhman DV, Farag MA, Joel TS, Gregory DM, Pedro M, Richard AD, Lloyd WS. 2005. Metabolic profiling of Medicago truncatula cell cultures reveals the effects of biotic and abiotic elicitors on metabolism. Journal of Experimental Botany, 56: 323-336. DOI: https://doi.org/10.1093/jxb/eri058

Brou KG. 2014. Rôle des marqueurs phénoliques dans le pathosystème Manihot esculenta-Colletotrichum gloeosporioides. Thèse de doctorat, Université Nangui Abrogoua, Côte d'Ivoire, $241 \mathrm{p}$.

Brou KG, Mamyrbekova-Bekro JA, Dogbo DO, Gogbeu SJ, Bekro Y-A. 2010. Sur la composition phytochimique qualitative des extraits hydromethanoliques des feuilles de 6 cultivars de Manihot esculenta de Cote d'Ivoire, European Journal of Scientific Research, $\quad \mathbf{4 5}(2)$ : 200-211. http://www.eurojournals.com/ejrs.htm

Brou GK, Dogbo OD, N'Zué B, Zohouri PG, Mamyrbékova-Békro JA, Békro Y-A. 2012. Effet du glyphosate sur la biosynthèse des constituants phénoliques de Manihot esculenta Crantz. Revue de génie industriel, 8: 32-43.

Calatayud PA, Rahbé Y, Delobel B, KhuongHuu F, Tertuliano M, Rü BL. 1994. Influence of secondary compounds in the phloem sap of cassava on expression of antibiosis towards the mealybug Phenacoccus manihoti. Netherlands Entomological Society, 72: 47-57. DOI: https://doi.org/10.1111/j.1570-

7458.1994.tb01801.x

Caldo RA, Nettleton D, Peng J, Wise RP. 2006. Stage-specific suppression of basal defense discriminates barley plants containing fastand delayed-acting Mla powdery mildew resistance alleles. Mol Plant Microbe Interact, 19: 939-947. DOI: 10.1094/MPMI-19-0939

Chen LW, Wang YQ, Wei LC, Shi M, Chan YS. 2007. Chinese herbs and herbal extracts for neuroprotection of dopaminergic neurons and potential therapeutic treatment of parkinson's disease. CNS Neurol. Disord. Drug Targets, 6: 273-281. DOI: $10.2174 / 187152707781387288$

Crawford GH, Sciacca JR, James WD. 2004. Tea tree oil: cutaneous effects of the extracted oil of Melaleuca alternifolia. Dermatitis, 15: 59-66. DOI : 10.2310/6620.2004.04003

Djinadou AKA, Olodo NI, Adjanohoun A. 2018. Evaluation du comportement de variété améliorées de manioc riche en bêtacarotène au sud du Bénin. Int. J. Bio. Chem. Sci., 12(2): 703-715. DOI: https://dx.doi.org//10.4314/ijbcs.v12i2.8

Doehlemann G, Wahl R, Horst RJ, Voll LM, Usadel B, Poree F, Stitt M, PonsKühnemann J, Sonnewald U, Kahmann R. 2008. Reprogramming a maize plant: transcriptional and metabolic changes induced by the fungal biotroph Ustilago maydis. Plant J., 56: 181-195. DOI: 10.1111/j.1365-313X.2008.03590.x

Dohou N, Yamni K, Tahrouch S, Idrissi HL M., Badoc A, Gmira N. 2003. Screening phytochimique d'une endémique ibéromarocaine, Thymelaea lythroides. Bull. Sog. Pharm. Bordeaux, 61-78.

Dogbo DO, Gogbeu SJ, N'zue B, Ya KA, Zohouri GP, Mamyrbekova-Bekro JA, Bekro Y-A. 2012. Comparative activities of ammonia-lyase and tyrosine ammonialyase and phenolic compounds accumulated in cassava elicited cell. Africa Crop Science Journal, 20(2): 1021-9730.

Eichmann R, Hückelhoven R. 2008. Accommodation of powdery mildew fungi in intact plant cells. J. Plant Physiol., 165: 5-18.

DOI: https://doi.org/10.1016/j.jplph.2007.05.00 4

Ekou N. 2003. Etude socio-économique de la filière du manioc, coût de production, circuit de commercialisation, dans le grand Abidjan. ANADER, 27 p. 
Ekoumou C. 2003. Etudes phytochimique et pharmacologique de 5 recettes traditionnelles utilisées dans le traitement des infections urinaires et de la cystite. Thèse de Doctorat, Université de Bamako, Mali, $158 \mathrm{p}$.

FAO. 2013. Bilans alirnentaives : les 20 plus importants pays producteurs du manioc. Division de la Statistique, FAOSTAT, Série informatique, FAO, Rome, Italie.

Farag MA, Deavours BE, de Fatima A, Naoumkina M, Dixon RA, Sumner LW. 2009. Integrated metabolite and transcript profiling identify a biosynthetic mechanism for hispidol in Medicago truncatula cell cultures. Plant Physiology, 151:1096-1113. DOI:

www.plantphysiol.org/cgi/doi/10.1104/pp. 109.141481

Farag MA, Huhman DV, Dixon RA, Sumner LW. 2008. Metabolomics reveals novel pathways and differential mechanistic and elicitor-specific responses in phenylpropanoid and isoflavonoid biosynthesis in Medicago truncatula cell cultures. Plant Physiology, 146: 387-402. www.plantphysiol.org/cgi/doi/10.1104/pp. 107.148431

Gogbe DBF, Konan JN, Diabaté S, Konan EP, Koné B, Dogbo DO. 2016. Réaction phénolique de quatre clones de palmiers à huile inoculés par Fusarium oxysporum f. sp. elaedis. Int. J. Biol. Chim. Sci., 10(2): 486-496.

DOI: http://dx.doi.org/10.4314/ijbcs.v10i23

Guetsky R, Kobiler I, Wang X, Perlman N, Gollop N, Avilaquezada G, Hadar I, Prusky D. 2005. Metabolism of the flavonoid epicatechin by laccase of Colletotrichum gloeosporioides and its effect on pathogenicity on avocado fruits. Phytopathology, 95:1341-1348. DOI: 10.1094/PHYTO-95-1341

Grotewold E. 2006. The genetics and biochemistry of floral pigments. Annu. Rev. Plant Biol., 57: 761-780. DOI: 10.1146/annurev.arplant.57.032905.10524 8

Hawksworth DL, Sutton BC, Ainsworth GC. 1983. Ainsworth and bisbyes dictionary of fungi. England. J., 56: 181-195.

Howele M, Andree CT, Kouadio JNE, Kouabenan A, Arthur MA, Daouda K.
2014. Assessment of three cassava varieties responses to cassava bacterial blight (cbb) in the seven agro ecological zones of Côte d'Ivoire during a survey in 2017. Int. J. Adv. Res., 7(9): 1220-1230. DOI: 10.21474/IJAR01/9776

Jasin'ski M, Kachlicki P, Rodziewicz P, Figlerowicz M, Stobiecki M. 2009. Changes in the profile of flavonoid accumulation in Medicago truncatula leaves during infection with fungal pathogen Phoma medicaginis. Plant Physiology and Biochemistry, 47: 847-853. https://doi.org/10.1016/j.plaphy.2009.05.0 04

Jones JDG, Dangl JL. 2006. The plant immune system. Nature, 444: 323-329. DOI: 10.1038/nature05286

Konan ED, Kouabenan A, Béket SB, Tchoa K, William JLA, Daouda K, Mongomaké K. 2017. Caractérisation agronomique de 44 accessions de manioc (Manihot esculenta Crantz) cultivés en Côte d'Ivoire. Int. J. Biol. Sci., 11(1): 174-184. DOI: http://dx.doi.org/10.4314/ijbcs.v11i1.14

Louis I, Cooke RC. 1985. Enzymes in the conidial matrix of Colletotrichum gloeosporioïdes and Ycospha erellapinodes. Transactions of the British Mycological Society, 84: 742-745. https://doi.org/10.1016/S00071536(85)80135-2

Lozovaya VV, Lygin AV, Zernova OV, Li, SX, Hartman GL, Widholm JM. 2004. Isoflavonoid accumulation in soybean hairy roots upon treatment with Fusarium solani. Plant Physiology and Biochemistry, 42(7-8): 671-679. DOI: 10.1023/B:PLAN.0000023666.30358.ae

Mancilla G, Jime'nez-TD, Femeni'a-Ri'os M, Maci'as-Sa'nchez AJ, Collado IG, Herna'ndez-Gala'n R. 2009. Novel macrolide from wild strains of the phytopathogen fungus Colletotrichum acutatum. Natural Product Reports, 4: 395398. DOI: $10.1177 / 1934578 X 0900400316$

Manso J-MM. 2005. Etude socio-économique de la filière du manioc à Tchimou-Assekro et dans les villages environnants. Cellule d'Analyse de Politiques Economiques du CIRES, Bouake, Côte d'Ivoire, 34p.

Masella R, Di Benedetto R, Vari R, Filesi C, Giovannini C. 2005. Novel mechanisms of 
natural antioxidant compounds in biological systems: involvement of glutathione and glutathione-related enzymes. J. Nutr. Biochem., 16: 577-586. DOI: 10.1016/j.jnutbio.2005.05.013

McRae CF, Stevens GR. 1990. Role of conidial matrix of Colletotrichum orbiculare in pathogenesis of Xanthium spinosum. Mycological Research, 94: 890-896. https://doi.org/10.1016/S09537562(09)81302-6

Naoumkina M, Farag MA, Sumner LW, Tang Y, Liu C-J, Dixon RA. 2007. Different mechanisms for phytoalexine induction by pathogen and wound signals in Medicago truncatula. Proceedings of the National Academy Sciences, 104: 17909-17915. https://doi.org/10.1073/pnas.0708697104

Muth D, Kachlicki P, Krajewski P, Przystalski M, Stobiecki M. 2009. Differential metabolic response of narrow leafed lupin (Lupinus angustifolius) leaves to infection with Colletotrichum lupini. Metabolomics, 5: 354-362. DOI: 10.1007/s11306-0090162-6

Onzo A, Zannou ID, Oloushègoun AJDA, Broutani S, Hanna R. 2012. Potentialité de l'acarien prédateur Amblyseius swirskii (Anthias-Henriot) (Acari: Phytoséiidae) dans la lutte biologique contre la mouche blanche Bemisia tabaci (Genn.), vecteur de la mosaïque du manioc en Afrique. Int. J. Biol. Chem. Sci., 6(6): 5085-5102. DOI: http://dx.doi.org/10.4314/ijbcs.v6i6.27

Panstruga R. 2003. Establishing compatibility between plants and obligate biotrophic pathogens. Curr. Opin. Plant Biol., 6: 320326. DOI: 10.1016/S1369-5266(03)000438

Perfect SE, Hughes HB, O'Connell RJ, Green JR. 1999. Colletotrichum: A model genus for studies on pathology and fungal-plant interactions. Fungal Genet Biol., 27: 189-
198.

DOI:

https://doi.org/10.1006/fgbi.1999.1143

Von Arx JA. 1981. The Genera of Fungi Sporulating Pure Culture, Cramer $\left(3^{\text {ème }}\right.$ edn). ErgodeBooks Ships: USA.

Suzuki H, Srinivasa RMS, Naoumkina M. 2005. Methyl jasmonate and yeast elicitor induce differential transcriptional and metabolic re-programming in cell suspension cultures of the model legume Medicago truncatula. Planta, 220: 696707. DOI: 10.1007/s00425-004-1387-2

Schmitt CA, Dirsch VM. 2009. Modulation of endothelial nitric oxide by plant-derived products. Nitric Oxide, 21: 77-91. DOI: 10.1016/j.niox.2009.05.006

Schliemann W, Ammer C, Strack D. 2006. Metabolite profiling of mycorrhizal roots of Medicago truncatula. Phytochemistry, 69: 112-146.

Singleton VL, Rossi JA. 1965. Colorimetry of total phenolics with phosphomolybdicphosphotungstic acid reagents. Am. J. Enol. Vitic., 16(3): 144-158.

Terry ER, Doku EV, Arene OB, Mahungu NM. 1983. Plantes-racines tropicales: culture et emplois en Afrique. actes du second symposium triennal de la société internationale pour les plantes-racines tropicales, Douala, Cameroun, 75-80.

Wojakowska A, Muth D, Dorota N, Cezary M, Stobiecki M, Kachlicki P. 2013. Change of phenolic secondary metabolite profiles in the reaction of narrow leaf lupin (Lupinus angoustifolius) plants to infections with Colletotrichum lupine fungus treatment with its toxin. Metabolomics, 9: 575-589. DOI: $10.1007 / \mathrm{s} 11306-012-0475-8$

Xinzhang, Guangdao Y, Jie Y, Qinglong S. 2012. Physiological mechanism of resistance to anthracnose of different Camellia varieties African Journal of Biotechnology, 11(8): 2026-203. DOI: 10.5897/AJB11.1099. 